
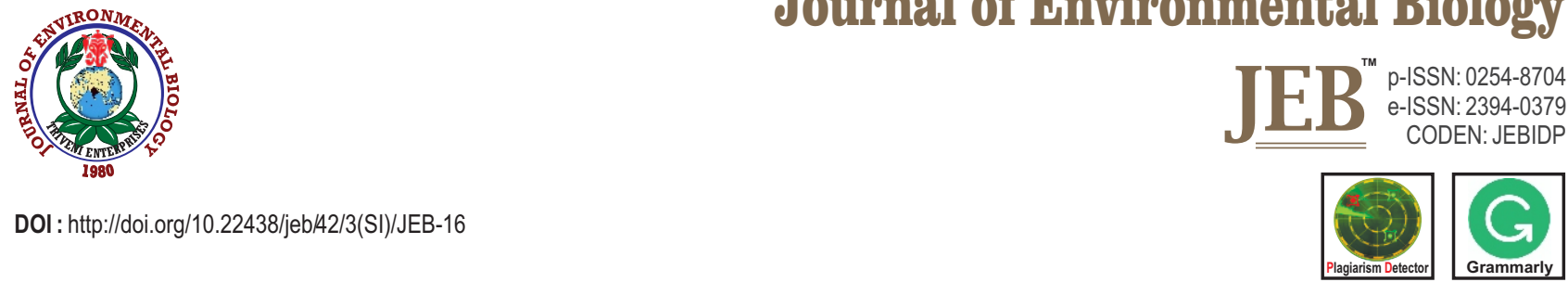

\title{
Variation in antibacterial properties of endophytic fungi isolated from Phaeophytes and Rhodophytes of Johor, Malaysia
}

\author{
N.F.A. Zainee ${ }^{1}$, N. Ibrahim ${ }^{2}$, N. Hidayah ${ }^{1}$ and M. Rozaimi ${ }^{1 *}$ \\ 'Department of Earth Sciences and Environment, Faculty of Science and Technology, Universiti Kebangsaan Malaysia, Bangi, 43600, Malaysia \\ ${ }^{2}$ Department of Biological Sciences and Biotechnology, Faculty of Science and Technology, Universiti Kebangsaan Malaysia, Bangi, 43600, \\ Malaysia \\ *Corresponding Author Email : mdrozaimi@ukm.edu.my
}

\begin{abstract}
Aim: To identify endophytic fungi of tropical macroalgae and analyse variation in antibacterial activity.

Methodology: Endophytic fungi were aseptically isolated from macroalgae tissue, identified by macroscopic and microscopic observations, screened for the presence of antibacterial activity using cross streak and disc diffusion methods against six human pathogenic bacteria.

Results: A total of 27 endophytic fungi were isolated and identified from 7 species of macroalgae collected from the Johor coast, Malaysia. Twenty-three fungal isolates belonged to Ascomycota, while two belonged to Zygomycota and Oomycota, respectively. Aspergillus niger was the most common and abundant endophyte found in macroalgal samples. Preliminary screening determined 13 species $(48.15 \%)$ having positive antibacterial activity. Quantitative analysis of antibacterial activity showed significant differences $(p<0.01)$ against six human pathogenic bacteria. Two fungal isolates indicated strong and broad-spectrum antibacterial activity namely, Pythium sp. and Trichoderma viride.

Interpretation: The findings demonstrate that certain macroalgae-derived endophytic fungi from Johor possess antibacterial properties and can be potentially new antibiotic sources, which are hitherto under-reported.

Key word: Antibacterial activity, Endophyte, Microfungi, Seaweed
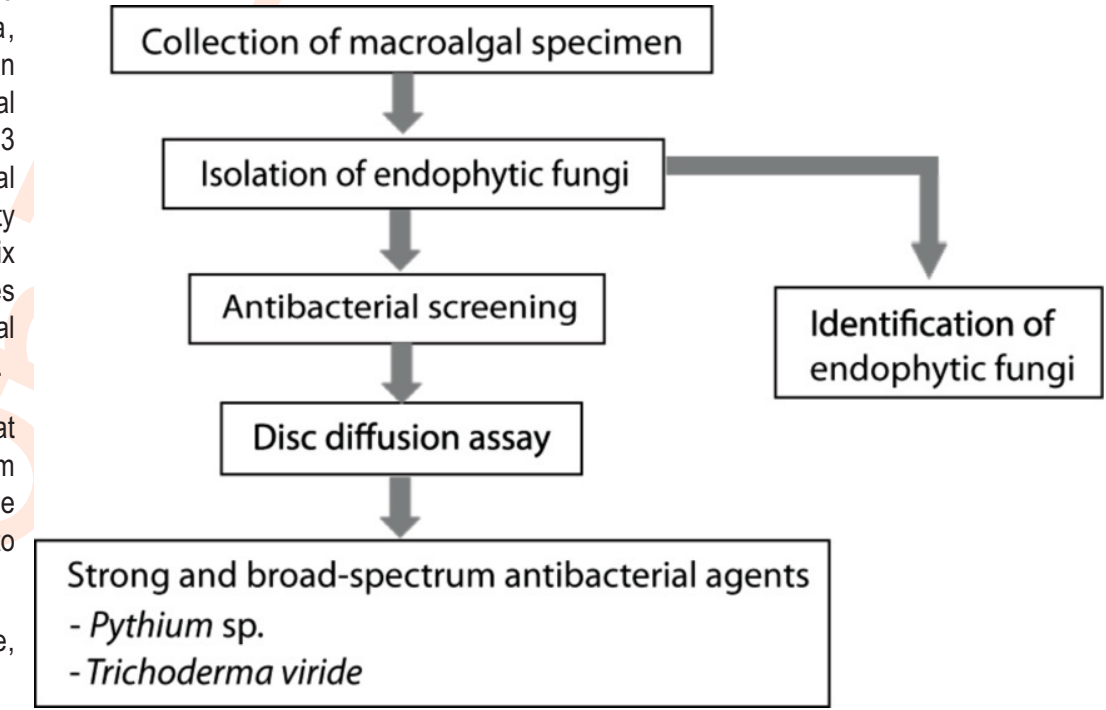

How to cite : Zainee, N.F.A., N. Ibrahim, N. Hidayah and M. Rozaimi: Variation in antibacterial properties of endophytic fungi isolated from Phaeophytes and Rhodophytes of Johor, Malaysia. J. Environ. Biol., 42, 840-848 (2021). 


\section{Introduction}

Antibiotic resistance is a global threat and widely recognised as one of the biggest risks to healthcare industry (Frieden, 2013; O'Neill, 2016). The World Health Organization (2019) has reported that the number of people requiring interventions against the risk of infectious disease is increasing up to 1582.9 million. In this sense, the current problem we are facing is the resistance of microorganisms towards antibiotics, which not only reduces the effectiveness of treatment, is also increasing the cost of treatment and mortality (O'Neill, 2016). This has led to the need for exploring new sources of antibacterial substances from natural environment, which is still underexplored for the treatment of modern infections (Wohlleben et al., 2016).

Endophytes from natural environment are potential sources of bioactive metabolites for new antibiotic substances (Radic and Strukelj, 2012; An et al., 2013). Metabolites from the natural environment are valuable sources of therapeutic agents due to their effectiveness, low toxicity and environmental impacts (Bagchi and Banerjee, 2014; Strobel, 2002). Endophytic fungi in terrestrial and ocean ecosystems have attracted researchers to exploit them as alternative source for pharmaceuticals (Al-Saif et al., 2014; Ariffin et al., 2011, 2014; Zainuddin et al., 2010).

Symbiosis between fungi and macroalgae produces a mutualistic relationship. The presence of endophytic fungi within the host has various functions depending on the microhabitat of fungi within the host (Chai et al., 2016). Endophytic fungi are able to promote the growth of their host (Bilal et al., 2018). Endophytes provide a variety of defence systems to the host such as reducing herbivory levels and increasing resistance to pathogens and pests (Bamisile et al., 2018). Endophytic fungi increases the resilience of host from extreme marine environmental conditions such as desiccation and drought, particularly during low tides when intertidal macroalgae are exposed for 8 hrs (Wicklow et al., 2005). The ability to survive in a high-stress environment is one of the factors that allows endophytic fungi to have a high degree of resistance and tolerance to extreme environmental changes (Waqas et al., 2015). Moreover, the endophytic fungi colonised in macroalgal thallus has the ability to mimic and improve the quality of copied metabolite compounds produced by its host (Radic and Štrukelj, 2012). In addition, endophytic fungi help the host in terms of nutrient absorption and increase resistance to predators and herbivores (Suryanarayanan, 2012).

Most of the microbial diversity studies have been conducted on the endophytic fungi of higher plants (Maadon et al., 2018), especially those that have ethnobotanical values (Nalini et al., 2014). Seagrasses recorded low frequency of colonisation but produced secondary metabolites that are capable of inhibiting pathogenic bacterial growth (Supaphon et al., 2013). In Malaysia, the studies on microfungi associated with macroalgae include testing for their anticancer (Ariffin et al., 2011), antioxidant (Ariffin et al., 2014) and antibacterial potentials (Zainee et al., 2018, 2019a, 2019b). However, very limited reports are available on the variation of endophytic fungi of macroalgae. This study, in line with the quest to discover new alternatives from natural sources for antibiotic production, explores the effectiveness of endophytic fungi isolated from macroalgae as antibacterial agents against human pathogenic bacteria.

\section{Materials and Methods}

Collection of macroalgae and seawater: Macroalgal specimens (including Dictyopteris divaricata, Gracilaria blodgetti, G. salicornia, Padina minor, Ulva lactuca, Sargassum oligocystum and S. polycystum) were collected during sampling in June 2015 at four different locations of Johor coast: Pulau Merambong; Nusajaya; Tanjung Dato and Tanjung Lompat (Fig. 1). The specimens were aseptically hand-collected, transferred into zip-lock plastic bags and kept at $4^{\circ} \mathrm{C}$ in an ice box. Seawater was collected at 0.5 to $1 \mathrm{~m}$ depth from the surface to prevent cross-contamination of microorganism from sediment and benthic organisms. The collected seawater was filtered, autoclaved and used for cleaning macroalgae thallus during surface sterilisation protocols.

Isolation of endophytic fungi: The macroalgal specimen was washed with sterilised seawater for $1 \mathrm{~min}$ and then was squarecut into $1 \mathrm{~cm} \times 1 \mathrm{~cm}$ using sterilised surgical blades. Surface sterilisation was done by soaking the specimen as follows: $75 \%$ ethanol (30 sec), 5\% sodium hypochlorite (30 sec) and 75\% ethanol (10 sec). The specimen was blot-dried using tissues to remove alcohol residue and transferred onto potato dextrose agar (PDA: Oxoid, USA). Six replicates of macroalgae specimens were incubated for $7-14$ days at $30^{\circ} \mathrm{C}$. Inspection for any evidence of fungal growth was done periodically.

Identification of endophytic fungi: Endophytic fungi were prepared for microscopic observation using Henrici slide technique with mycelium stained using lactophenol cotton blue dye. Morphological characteristics of endophytic fungi such as spore structure, hyphae and mycelium were observed using light microscope (Leica, US). Macroscopic observation was done to differentiate the endophytes' morphology for species identification. This include features of ascospore and peridium morphology, odour, colour, and zoning, which were compared against morphological traits in published observations (Zainee et al., 2019a; CLSI, 2015)

Antibacterial screening: Cross streak method was performed to screening antibacterial potentials of endophytic fungi. Fungal mycelium at late exponential phase of fungal growth (20-30 days old), were cut into $6 \mathrm{~cm} \times 1 \mathrm{~cm}$ portions using sterile surgical blades and transferred onto the middle of Mueller Hinton Agar (MHA; Oxoid, USA). Screening was done against six bacterial 


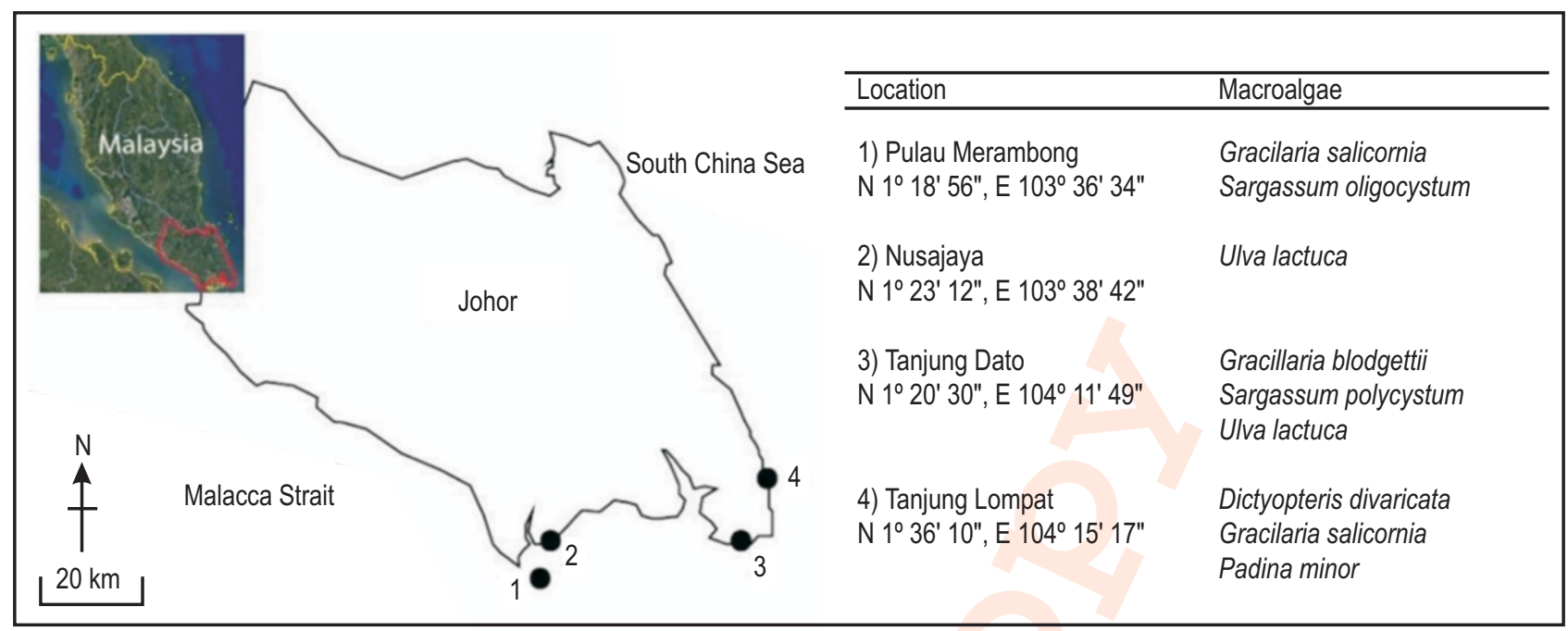

Fig. 1 : Location of sampled macroalgae along the Johor coast: (1) Pulau Merambong; (2) Nusajaya; (3) Tanjung Dato and (4) Tanjung Lompat.

species obtained from Microbiology Laboratory, UKM including Gram-positive bacteria (Staphylococcus aureus) and Gramnegative bacteria, namely Serratia marcescens, Salmonella typhi, Shigella sp., Escherichia coli and Klebsiella pneumoniae. Turbidity of bacterial suspension was adjusted to $0.5 \mathrm{McF}$ arland standard solution (equal to $10^{8}$ colony forming unit (CFU) $\mathrm{ml}^{-1}$ ). Bacterial suspensions were streaked $(3 \mathrm{~cm}$ in length) using a sterile cotton swab on MHA perpendicular to fungal-cut agar. Triplicate of each fungal species were incubated at $30^{\circ} \mathrm{C}$ for 24 hrs. Fungi that were able to inhibit the growth of bacteria were later tested for antibacterial activity using disc diffusion assay.

Disc Diffusion Assay: The assay was performed as per the Guidelines of the Clinical Laboratory Standards Institute (CLSI, 2015). Interpretative charts were used to classify the sensitivity level of antimicrobial agents into susceptible (inhibition zone, $\geq 22$ $\mathrm{mm}$ ), intermediate (inhibition zone, $15-21 \mathrm{~mm}$ ) and resistant (inhibition zone, $<15 \mathrm{~mm}$ ) (CLSI, 2015).

Statistical Analysis: The differences in the antibacterial activity of endophytic fungi species on each bacterial strain were tested by One-way PERMANOVA test followed by post hoc tests (PERMANOVA pairwise comparisons). The data were analysed according to single factor design (endophytic fungi) using Euclidean distance similarity matrices generated from transformed square-root data and was tested by the Monte Carlo tests using 999 per mutations under unrestricted permutation of raw data. This analysis was conducted using Primer-E (Version $6)$.

\section{Results and Discussion}

Fungal endophytes colonising marine plants are reservoirs of novel bioactive secondary metabolites, potentially for the pharmaceutical industry (Zainee et al., 2018). In this study, the effectiveness of endophytic fungi isolated from macroalgae as antibacterial agents has been reported. The endophytic fungi species studied responded differently to human pathogenic bacteria and it was found that some fungal species were relatively more effective as agents for exerting antibacterial activity. Furthermore, a new occurrence of Pythium sp. in the marine environment is reported herein, and this endophyte represents the most effective antibacterial agent against human pathogenic bacteria among the other fungi studied.

Twenty-seven endophytic fungi species were isolated from 7 species of macroalgae collected from Johor coastal areas (Fig. 1). Twenty-three fungal isolates belonged to Ascomycota with two each belonged to Zygomycota and Oomycota, respectively. Green algae, Ulva lactuca recorded the highest number of fungal isolates (7 species), followed by Sargassum polycystum (6 species), Gracilaria salicornia (5 species), Sargassum oligocystum (4 species), Gracilaria blodgetii (2 species), Padina minor (2 species) and Dictyopteris divaricata (1 species). Aspergillus niger was dominant in almost all the macroalgal host, whilst Pythium sp. was a rare species and recorded only once in Ulva lactuca.

Screening of antibacterial activity against six tested human pathogenic bacteria revealed that $48.15 \%$ (13 out of 27 species) of the isolated macroalgae-endophytic fungi displayed antagonism activity against pathogenic bacteria (Table 1). Nine species showed active antibacterial activity against all human pathogenic bacteria. Four species namely Aspergillus niger, Penicillium notatum, P. rubens and Cunninghamella elegans showed active antibacterial activity up to five strains of human pathogenic bacteria only (Table 1). 
The antibacterial activity was further analysed by disc diffusion assay. Pairwise one-way PERMANOVA tests indicated that variation endophytic fungi antibacterial activity was significantly different $(p<0.01)$ on each of the bacterial strains (Table 2). Our results indicated strong and broad-spectrum antibacterial activities of two fungal isolates (Pythium sp. and Trichoderma viride) isolated from Ulva lactuca and Sargassum polycystum, respectively. These endophytes were able to destroy pathogenic bacteria by forming susceptible type of inhibition against tested bacterial strains. Statistical analysis showed significant difference $(p<0.01)$ between endophytic fungi species (Supplementary Material S1) to inhibit the pathogenic bacteria.

In this study, Pythium sp. isolated from Ulva lactuca produced the largest inhibition zone against three bacteria species, namely Shigella sp., E. coli and S. aureus $(66.17 \mathrm{~mm}$, $49.83 \mathrm{~mm}$ and $45.75 \mathrm{~mm}$ ), respectively, followed by $S$. marcescens (32.00 mm), and S. typhi (29.00 mm) (Table 3). No inhibition was shown against $K$. pneumoniae. The strong antibacterial activity of Pythium has been reported as a key ability of these fungi in resisting pathogenic bacteria (Herrero et al., 2020).

The microbial diversity associated with Ulva has been reported (Esthela et al., 2012). Ulva lactuca extract itself is capable of exhibiting a broad-spectrum and strong antibacterial activity against various pathogenic bacteria (Deveau et al., 2016; Kim et al., 2007). Bacterial endophytes of Ulva are implicated in the presence of various bioactive compounds (Hollants et al., 2013). Compounds from marine algae may play an important role in the formation of many other bioactive secondary metabolites, which exhibit inherent antibacterial activity (Al-Saif et al., 2014). Endophytic fungi have been reported to produce similar compounds produced by the host (Tayung et al., 2011). This suggests that Pythium sp. isolated may have adapted to produce same secondary metabolite compounds found in Ulva. Interestingly, there was a rare observation of green pigment formed around the inhibition zone of Pythium disk (Fig. 2). According to Tan et al. (2018), the pigment resulted from the antagonistic response of fungi in the presence of bacteria, likely

Table 1 : Antibacterial screening of macroalgae-derived endophytic fungi using cross-streak method (+ active; -: inactive)

\begin{tabular}{|c|c|c|c|c|c|c|c|}
\hline \multirow[t]{2}{*}{ Fungal endophyte isolate } & \multirow[t]{2}{*}{ Macroalgae (Host) } & \multicolumn{5}{|c|}{ Inhibition zone } & \multirow[b]{2}{*}{ E. coli } \\
\hline & & S. aureus & S. typhi & S. marcescens & K. pneumoniae & Shigella sp. & \\
\hline \multicolumn{8}{|l|}{ Ascomycota } \\
\hline Fusarium solani & Gracilaria salicornia & + & + & + & + & + & + \\
\hline F. oxysporum & Padina minor & + & + & + & + & + & + \\
\hline F. semitectum & Ulva lactuca & - & - & - & - & - & - \\
\hline Paecilomyces lilacinus & Ulva lactuca & - & - & - & - & - & - \\
\hline P. variotii & Gracilaria salicornia & - & - & - & - & - & - \\
\hline Trichoderma viride & Sargassum polycystum & + & + & + & + & + & + \\
\hline Aspergillus flavus & Ulva lactuca & + & + & + & + & + & + \\
\hline A. fumigatus & Gracilaria blodgettii & + & + & + & + & + & + \\
\hline A. oryzae & Sargassum polycystum & - & - & - & - & - & - \\
\hline A. terreus & Sargassum oligocystum & + & + & + & + & + & + \\
\hline A. nidulans & Gracilaria salicornia & + & + & + & + & + & + \\
\hline A. niger & Sargassum polycystum & + & + & + & - & + & + \\
\hline A. versicolor & Sargassum oligocystum & - & - & - & - & - & - \\
\hline Penicillium citrinum & Padina minor & + & + & + & + & + & + \\
\hline P. chrysogenum & Gracilaria salicornia & - & - & - & - & - & - \\
\hline P. digitatum & Sargassum oligocystum & - & - & - & - & - & - \\
\hline P. expansum & Ulva lactuca & - & - & - & - & - & - \\
\hline P. notatum & Sargassum polycystum & + & - & + & + & + & + \\
\hline P. rubens & Sargassum polycystum & + & + & - & + & + & + \\
\hline P. roqueforti & Ulva lactuca & - & - & - & - & - & - \\
\hline Trichophyton rubrum & Sargassum polycystum & - & - & - & - & - & - \\
\hline Pseudallescheria boydii & Gracilaria blodgettii & - & - & - & - & - & - \\
\hline $\begin{array}{l}\text { Trichothecium roseum } \\
\text { Zygomycota }\end{array}$ & Gracilaria salicornia & - & - & - & - & - & - \\
\hline Cunninghamella elegans & Sargassum oligocystum & + & + & + & - & + & + \\
\hline $\begin{array}{l}\text { Rhizopus sp. } \\
\text { Oomycota }\end{array}$ & Ulva lactuca & - & - & - & - & - & - \\
\hline Pythiumsp. & Ulva lactuca & + & + & + & + & + & + \\
\hline Phytopthorasp. & Dictyopteris divaricata & - & - & - & - & - & - \\
\hline
\end{tabular}


by producing secondary metabolite substances. Therefore, this is the first report of Pythium forming secondary metabolite substances with green pigmentation, which may be associated with the virulence factor of this fungus.

Trichoderma viride is grouped as a wide-spectrum fungus and has been reported as an endophytic fungi in the brown algae Sargassum (Zainee et al., 2019b). The fungus has an ability to produce or release a variety of compounds that induces localised or systemic resistance responses, explaining their lack of pathogenicity towards plants (Leelavathi et al., 2014). It shows effectiveness as an antibacterial agent that produces strong antibacterial activity second to Pythium. Sadykova et al. (2015) and Saleh et al. (2011) have reported that Trichoderma produced wide-spectrum antibacterial activity with strong bacterial susceptibility. Isolates of Trichoderma from another brown algae (Padina sp.) showed inhibition zone against S. aureus (12.8$17.09 \mathrm{~mm}$ ) and $E$. coli $(13.60 \mathrm{~mm}$ ) (Handayani et al., 2019). However, this study had recorded larger inhibition zones with susceptible-type of inhibition than those, achieving $48.58 \mathrm{~mm}$ against $S$. aureus, followed by E. coli $(37.33 \mathrm{~mm})$, S. marcescens (31.17 mm), Shigella sp. (24.00 mm) and S. typhi (22.42 mm), while eliciting intermediate susceptibility from $K$. pneumoniae (17.50 mm) (Table 3).

Aspergillus isolates were most commonly found in the tissues of six macroalgal (Zainee et al., 2018). According to Barakat and Gohar (2012), Aspergillus is the largest fungal group producing metabolite compounds with antibacterial activity. In this study, all tested fungal isolates produce broad-spectrum antibacterial activity, except for Aspergillus fumigatus. A. fumigatus showed activity towards Gram-negative bacteria only and may be classified as narrow-spectrum activity. Zainuddin et al. (2010) stated that Gram-positive bacteria were easily inactivated $(86.7 \%)$ by marine-derived fungi compared to Gramnegative bacteria (13.3\%). In contrast to terrestrial $A$. fumigatus isolates, inhibition $(20.67 \mathrm{~mm})$ against $S$. aureus, was smaller than the positive control (33 mm) (Furtado et al., 2002). Overall, Aspergillus generally produced resistant-type inhibition except for A. terreus. This species, among other Aspergillus species, formed the strongest inhibition towards Shigella sp. $(31.58 \mathrm{~mm}$, Table 3). A study by Barakat and Gohar (2012) recorded A. terreus successfully inhibited fish pathogenic bacteria with an inhibition zone of 15-30 mm, which contrasted from the findings

Table 2: One-way PERMANOVA test for variation of endophytic activity on selected bacterial strains. ${ }^{* *}=p<0.01$

\begin{tabular}{llllll}
\hline Bacterial strain & df & SS & MS & F & p \\
\hline S. aureus & 12 & 150.74 & 12.56 & 11.19 & $* *$ \\
S. typhi & 12 & 126.23 & 10.52 & 35.42 & $* *$ \\
S. marcescens & 12 & 148.17 & 12.35 & 49.30 & $*$ * \\
K. pneumoniae & 12 & 73.27 & 6.10 & 4.05 & $* *$ \\
Shigella sp. & 12 & 137.51 & 11.46 & 11.20 & $* *$ \\
E. coli & 12 & 221.10 & 18.43 & 1179 & $* *$ \\
\hline
\end{tabular}

Table 3 : Antibacterial activity of endophytic fungi isolated from macroalgae using Kirby-Bauer Method. The fungal disk diameter was $6.00 \mathrm{~mm}$; data that showed this value means no zone of inhibition was observed.

\begin{tabular}{|c|c|c|c|c|c|c|c|c|}
\hline \multirow{2}{*}{$\begin{array}{l}\text { Endophytic fungi } \\
\text { isolates }\end{array}$} & \multicolumn{6}{|c|}{ Inhibition zone (mm) } & \multicolumn{2}{|c|}{ Control } \\
\hline & S. aureus & S. typhi & S. marcescens & K. pneumoniae & Shigella sp. & E. coli & Positive & Negative \\
\hline Aspergillus flavus & $13.50 \pm 0.33$ & 6.00 & 6.00 & $16.83 \pm 0.27$ & $17.16 \pm 0.26$ & $13.17 \pm 0.23$ & $27.27 \pm 0.13$ & 0.00 \\
\hline A. fumigatus & 6.00 & $16.83 \pm 0.41$ & 6.00 & 6.00 & $14.58 \pm 0.25$ & $14.50 \pm 0.29$ & $29.55 \pm 0.52$ & 0.00 \\
\hline A. nidulans & $16.16 \pm 0.78$ & 6.00 & $8.83 \pm 0.10$ & $11.67 \pm 0.19$ & $17.50 \pm 0.80$ & 6.00 & $12.31 \pm 0.17$ & 0.00 \\
\hline A. niger & 6.00 & 6.00 & 6.00 & 6.00 & 6.00 & 6.00 & $27.92 \pm 0.31$ & 0.00 \\
\hline A. terreus & $9.50 \pm 0.09$ & 6.00 & 6.00 & $16.58 \pm 0.36$ & $31.58 \pm 1.36$ & $16.5 \pm 0.26$ & $37.58 \pm 0.29$ & 0.00 \\
\hline Cuninghamella elegans & $25.83 \pm 0.97$ & $16.83 \pm 0.37$ & $9.42 \pm 0.08$ & 6.00 & $24.33 \pm 0.54$ & $21.67 \pm 0.42$ & $24.23 \pm 0.12$ & 0.00 \\
\hline Fusarium oxysporum & $21.92 \pm 0.25$ & $9.42 \pm 0.08$ & $15.75 \pm 0.32$ & $11.67 \pm 0.19$ & $30.83 \pm 0.50$ & 6.00 & $31.10 \pm 0.21$ & 0.00 \\
\hline F. solani & $22.58 \pm 0.65$ & $17.50 \pm 0.26$ & $16.00 \pm 0.31$ & $16.25 \pm 1.26$ & $11.67 \pm 0.26$ & $32.50 \pm 1.38$ & $29.17 \pm 0.39$ & 0.00 \\
\hline Penicillium citrinum & $20.17 \pm 1.02$ & 6.00 & 6.00 & 6.00 & $8.92 \pm 0.08$ & 6.00 & $23.04 \pm 0.41$ & 0.00 \\
\hline P. notatum & $13.00 \pm 0.17$ & 6.00 & $25.92 \pm 2.50$ & $17.25 \pm 0.29$ & $14.58 \pm 0.27$ & 6.00 & $23.13 \pm 0.29$ & 0.00 \\
\hline P.rubens & $17.76 \pm 0.32$ & $14.53 \pm 0.17$ & $18.17 \pm 0.31$ & $14.75 \pm 0.08$ & $19.50 \pm 0.37$ & 6.00 & $27.33 \pm 0.37$ & 0.00 \\
\hline Pythium sp. & $45.75 \pm 2.96$ & $29.00 \pm 1.35$ & $32.00 \pm 1.21$ & 6.00 & $66.17 \pm 4.47$ & $49.83 \pm 4.01$ & $31.57 \pm 0.32$ & 0.00 \\
\hline Trichoderma viride & $48.58 \pm 1.30$ & $22.42 \pm 0.47$ & $17.33 \pm 0.38$ & $17.50 \pm 0.42$ & $24.00 \pm 0.61$ & $37.33 \pm 1.17$ & $33.35 \pm 0.17$ & 0.00 \\
\hline
\end{tabular}

mean of inhibition zone \pm S.E.M $(n=3)$ 

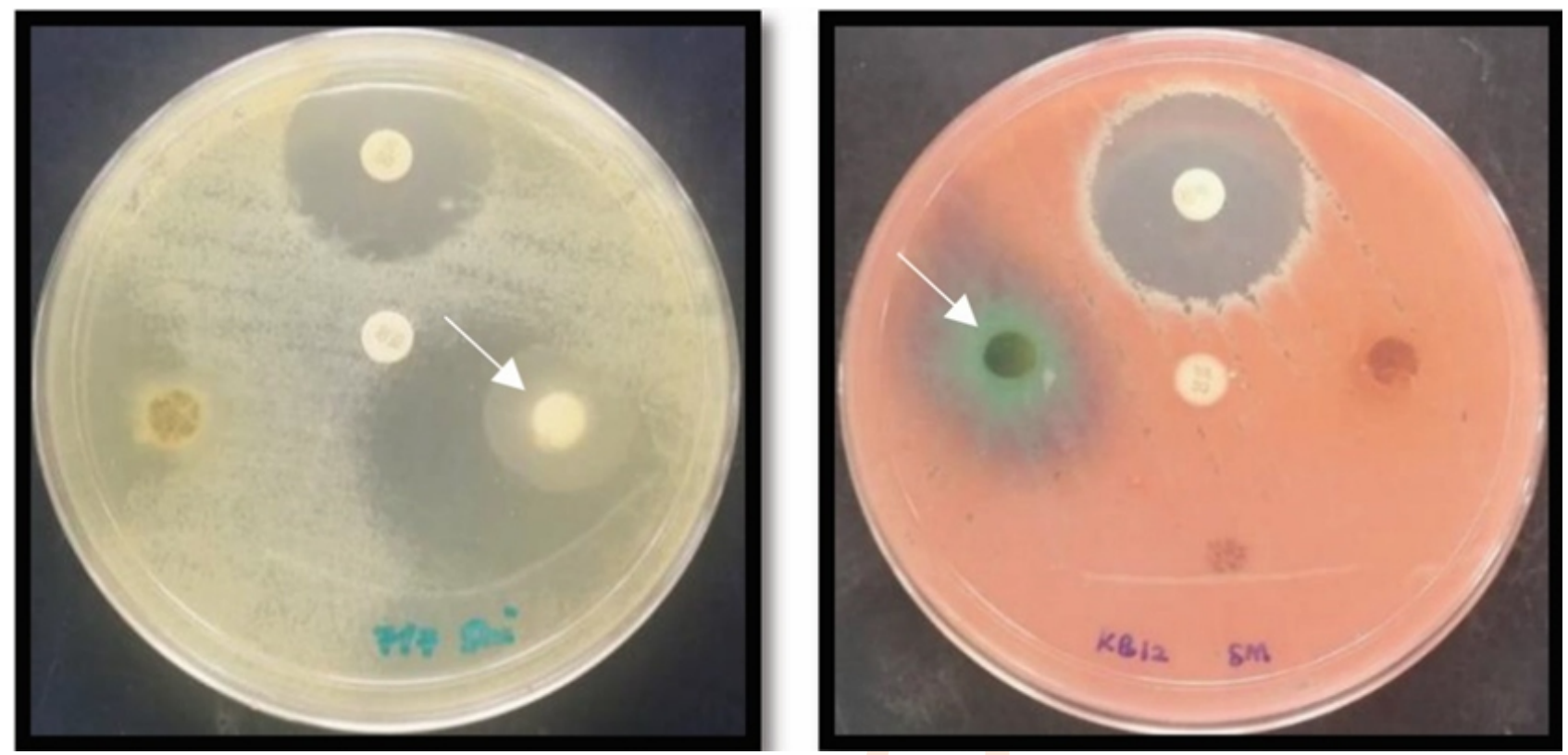

Fig. 2 : (Left). Aspergillus terreus mycelial growth around the disc on Shigella sp. lawn. (Right). Green pigment formation around Pythium sp. disc on Serratia marcescenslawn.

showing that isolates have high susceptibility levels. Interestingly, a rare observation of mycelial growth were observed around $A$. terreus disk on MHA of Shigella lawn (Fig. 2). According to Mueller et al. (2004), this may be a result of the fungus producing secondary metabolites during the lag phase of growth.

Kalyani and Hemalatha (2017) reported that A. niger produced small inhibition zones towards $S$. aureus, $K$. pneumoniae and $E$. coli, which contrasted our findings. Although A. niger was recorded in this study as the dominant endophyte in macroalgae, this fungus did not show antibacterial activity (Table 1). On the other hand, $A$. flavus and $A$. nidulans recorded weak antibacterial activity towards all tested pathogen (Table 3 ). There was no significant differences ( $p>0.05$ ) in size of inhibition zone for $A$. flavus and $A$. nidulans against all bacterial strains except for $E$. coli. This is congruent with isolation studies of marine fungi from the South China Sea (Zhang et al., 2013), which showed that $56 \%$ of fungi (including Aspergillus and Penicillium) had strong antibacterial activity against pathogenic bacteria.

In previous research, penicillin-like substances were isolated from $P$. notatum associated with the brown algae Sargassum ringgoldianum (Amagata et al., 1998). In addition, Leitão and Enguita (2016) stated that sodium chloride ions present in marine environment enhances the production of high quality antibacterial substances in Penicillium. In this study $S$. marcescens was susceptible to the growth of $P$. notatum $(25.92$ $\mathrm{mm}$ ), while K. pneumoniae, Shigella sp. and $S$. aureus showed relatively more resistant responses $(17.25 \mathrm{~mm}, 14.58 \mathrm{~mm}$, and $13.00 \mathrm{~mm}$, respectively). Pairwise analysis showed significant difference $(p<0.01)$ of $P$. notatum and $P$. rubens against $S$. marcescens. $P$. rubens exerted weak inhibition against all tested pathogen, with a slight inhibition compared to the positive control (Table 3). Compaore et al. (2016) reported that, P. citrinum was capable to produce citrinin, which is a broad spectrum antibiotic, especially against Gram-positive bacteria. However, in this study $P$. citrinum elicited an intermediate susceptibility response towards Gram-negative bacteria $S$. aureus $(20.17 \mathrm{~mm})$, and a weak response towards Gram-negative bacteria Shigella $\mathrm{sp}$. (8.92 mm). Whilst, S. typhi, S. marcescens, K. pneumoniae and E. coli showed no formation of inhibition zones around the disk for P. citrinum (Table 3).

Fusarium solani was effective against $E$. coli $(32.50 \mathrm{~mm})$ and formed intermediate susceptibility towards $S$. aureus (22.58 $\mathrm{mm}$ ), whilst exhibiting weak antibacterial activity against $S$. typhi (17.5 mm), S. marcescens (16.00 mm), K. pneumoniae (16.25 $\mathrm{mm}$ ) and Shigella sp. (11.67 mm) (Table 3). This differs from the findings of Kyekyeku et al. (2017), wherein F. solani colonies did not produce any inhibition towards $S$. aureus. Similar to Rahaweman et al. (2016), Fusarium isolates cultivated had produced inhibition zone of $11.0 \mathrm{~mm}$ and $4.0 \mathrm{~mm}$ against $S$. aureus and $E$. coli, respectively. These comparisons indicate that the endophytes in this study produced stronger inhibition compared to other studies. There was a significant difference in the pairwise test between $F$. oxysporum and $F$. solani against $E$. coli, where $p<0.01$. F. oxysporum showed no inhibition against $E$. coli, however, Shigella sp. (30.83 mm) formed susceptible inhibition, showing weak inhibition against $S$. aureus $(21.92 \mathrm{~mm})$, S. marcescens (15.75 mm), K. pneumoniae (11.67 mm) and $S$. 
typhi (9.42 mm) (Table 3), respectively. It is worth noting that Fusarium showed antimicrobial activities against pathogenic and multidrug-resistant bacteria, and these isolates were from environments with extreme conditions, including high nutrient pollution (Deshmukh et al., 2014), temperature and pH (Liu et al., 2012). Fusarium has been found in terrestrial sediment and proved as a good source of biologically active secondary metabolites (Jayasinghe et al., 2006; Schneider et al., 2008). Several studies have reported that Fusarium spp. isolated as plant endophytes play an important role in protecting plants (De Felício et al., 2015; Sondergaard et al., 2016). Zhang et al. (2016) reported that Fusarium had strong antimicrobial effects on in-vitro Pseudomonas aeruginosa by increasing the permeability of this bacterium's cell membranes. This suggests that Fusarium has the potential as a producer of antibacterial agent and can be a valuable source for the discovery of new drugs or agents for antimicrobial purposes.

Marcellano et al. (2017) had reported that Cunninghamella was among five isolated endophytes with strong antibacterial activity against $S$. aureus and E.coli, with inhibition zones of $10.4 \mathrm{~mm}$ and $9.7 \mathrm{~mm}$, respectively. In contrast, a larger inhibition zone elicited by Cunninghamella elegans was displayed in this study with classifications as susceptible against S. aureus $(25.83 \mathrm{~mm})$ and Shigella sp. $(24.33 \mathrm{~mm})$, intermediate response towards $E$. coli $(21.67 \mathrm{~mm})$, resistance towards S. typhi $(16.83 \mathrm{~mm})$ and $S$. marcescens $(9.42 \mathrm{~mm})$, and no antibacterial activity against $K$. pneumoniae (Table 3 ). The trend of this findings is similar to those of Ali et al. (1995), where Cunninghamella isolates from terrestrial plants produced effective antibacterial activity with inhibition zones of approximately $20-25 \mathrm{~mm}$.

Overall, this study demonstrates that endophytic fungi isolated from macroalgae exhibited strong inhibitory activity against a number of bacterial strains that are pathogenic to human health. This research may lead to the exploration of novel sources of antibacterial agents from the natural marine environment, which will fulfil the objectives of bioprospecting new sources of antibiotics. In this respect, the endophytic fungi isolated from the macroalgae that produced antibacterial agents should be further identified biochemically. It is suggested the evaluation of secondary metabolite compound produced by the macroalgal-derived endophytic fungi, this can be done by performing further phytochemical screenings for potential uses in the pharmaceutical industry, which is essential to fulfil the quest for new antibiotic compounds from natural sources.

\section{Acknowledgments}

This study was supported by the Universiti Kebangsaan Malaysia Research University grant (GUP-2016-055) and MyBrain Scholarship awarded to the first author by the Ministry of Higher Education, Malaysia. We would like to thank Assoc. Prof. Dr. Ahmad Ismail and Assoc. Prof. Dr. Asmida Ismail for advice in conducting the study, Mr Mohamed Effendi Taip for assistance during fieldwork, and the staff of Centre of Marine Ecology, EKOMAR for providing facilities for the research.

\section{Add-on Information}

Authors' contribution : N.F.A. Zainee: Conceptualization, data curation formal analysis, investigation, methodology, validation, visualization, writing: original draft, review and editing, $\mathbf{N}$. Ibrahim, M. Rozaimi: Conceptualization, funding acquisition, project administration, resources, supervision, validation, visualization, writing: review and editing, N. Hidayah: Investigation, validation, visualization, writing: review and editing.

Research content : The research content of manuscript is original and has not been published elsewhere.

\section{Ethical approval : NotApplicable}

Conflict of interest : The authors declare that there is no conflict of interest.

\section{Data from other sources : NotApplicable}

Consent to publish : All authors agree to publish the paper in Journal of Environmental Biology.

\section{References}

Al-Saif, S.S.A.L, N. Abdel-Raouf, H.A. El-Wazanani and I.A. Aref: Antibacterial substances from marine algae isolated from Jeddah coast of Red Sea, Saudi Arabia. Saudi J. Biol. Sci., 21, 57-64 (2014).

Ali, A., S. El-Sharkawy, J. Abdul Hamid, N. Ismail and M. Lajis: Antimicrobial activity of selected Malaysian plants. Pertanika J. Trop. Agric. Sci.,18, 57-61 (1995).

Amagata, T., K. Minoura and A. Numata: Cytotoxic metabolites produced by a fungal strain from a Sargassum alga. J. Antibiot., 51, 432-434 (1998).

An, C.Y., X.M. Li, C.S. Li, S.S. Gao, Z. Shang and B.G. Wang: Triazoles and other $\mathrm{N}$-containing metabolites from the marine-derived endophytic fungus Penicillium chrysogenum EN-118. Helv. Chim. Acta, 96, 682-687 (2013).

Ariffin, S.A., P. Davis and K. Ramasamy: Cytotoxic and antimicrobial activities of Malaysian marine endophytic fungi. Botanica Marina, 54, 95-100 (2011).

Ariffin, S.A., K. Ramasamy, P. Davis, V. Mani and M.A. Abdulla: Safety of Malaysian marine endophytic fungal extract S2 from a brown seaweed Turbinaria conoides. J. Coast. Life Med., 2, 527-534 (2014).

Bagchi, B. and D. Banerjee: Endophytic fungal diversity and their comparison in two woody climbers, from few regions of West Medinipur district, West Bengal, India. Int. J. Innov. Sci. Eng. Technol., 1, 434-443 (2014).

Bamisile, B.S., C.K. Dash, K.S. Akutse, R. Keppanan and L. Wang: Fungal endophytes: Beyond herbivore management. Front. Microbiol., 9, 544 (2018).

Barakat, K.M. and Y.M. Gohar: Antimicrobial agents produced by marine 
Aspergillus terreus var. africanus against some virulent fish pathogens. Indian J. Microbiol., 52, 366-372 (2012).

Barseghyan, G.S. and S.P. Wasser: Species diversity of hypogeous Ascomycetes in Israel. Mycobiology, 38, 159-165 (2010).

Bilal, L., S. Asaf, M. Hamayun, H. Gul, A. Iqbal, I. Ullah, I.J. Lee and A. Hussain: Plant growth promoting endophytic fungi Aspergillus fumigatus TS1 and Fusarium proliferatum BRL1 produce gibberellins and regulates plant endogenous hormones. Symbiosis, 76, 117-127 (2018).

Chai, X.Y., G.Q. Chai, Y.Y. Xiang, W.W. Zhang and P.F. Yin: Composition and ecological distribution of endophytic and epiphytic fungi from the foliage of Pteroceltis tatarinowii.Shengtai Xuebao/ Acta Ecol. Sin., 36, 5163-5172 (2016).

CLSI: Performance Standards for Antimicrobial Disk Susceptibility Tests; Approved Standard. $12^{\text {th }}$ Edn., CLSI, Wayne, PA, USA(2015).

Compaore, H., H. Sawadogo-lingani, F. Guira, S. Samandoulougou and A. Savadogo: Enhancement of antibacterial compounds production by Aspergillus flavus and Penicillium citrinum isolated from locals foods in Bobo dioulasso and Ouahigouya, Burkina faso. Eur. J. Pharm. Med. Res, 3, 354-363 (2016).

De Felício, R., G.B. Pavão, A.L.L. De Oliveira, C. Erbert, R. Conti, M.T. Pupo, N.A. Furtado, E.G. Ferreira, L.V. Costa-Lotufo, M.C.M. Young and N.S. Yokoya: Antibacterial, antifungal and cytotoxic activities exhibited by endophytic fungi from the Brazilian marine red alga Bostrychia tenella (Ceramiales). Rev. Bras. Farmacogn., 25,641-650 (2015).

Deshmukh, R., A. Mathew and H.J. Purohit: Characterization of antibacterial activity of bikaverin from Fusarium sp. HKF15. J. Biosci. Bioeng.,117, 443-448 (2014).

Deveau, A.M., Z. Miller-Hope, E. Lloyd, B.S. Williams, C. Bolduc, J.M. Meader, F. Weiss and K.M. Burkholder: Antimicrobial activity of extracts from macroalgae Ulva lactuca against clinically important Staphylococci is impacted by lunar phase of macroalgae harvest. Lett.Appl. Microbiol., 62, 363-371 (2016)

Esthela, I.S., L.V. Jesús, G.R. Guerra and N.E.S. Ayala: Bioactive compounds from bacteria associated to marine algae. In: Biotechnology: Molecular Studies and Novel Applications for Improved Quality of Human Life (Ed.: R. Sammour). Intech Open, London, United Kingdom (2012). doi:10.5772/27842

Frieden, T.: Antibiotic Resistance Threats in the United States, 2013.CDC, Control and Prevention, US Department of Health and Human Services, USA, pp. 11-28 (2013).

Furtado, N.A.J.C., S. Said, I.Y. Ito and J.K. Bastos: The antimicrobial activity of Aspergillus fumigatus is enhanced by a pool of bacteria. Microbiol. Res., 157, 207-211 (2002).

Handayani, D., N. Ananda, M.A. Artasasta, R. Ruslan, O. Fadriyanti and T.E. Tallei: Antimicrobial activity screening of endophytic fungi extracts isolated from brown algae Padina sp. J. Appli. Pharm., 9, 9-13 (2019).

Herrero, M.L., M.B. Brurberg, D.I. Ojeda and M.Y. Roleda: Occurrence and pathogenicity of Pythium (Oomycota) on Ulva species (Chlorophyta) at different salinities. Algae, 35, 79-89 (2020).

Hollants, J., F. Leliaert, H. Verbruggen, A. Willems and O. De Clerck: Permanent residents or temporary lodgers: Characterizing intracellular bacterial communities in the siphonous green alga Bryopsis. Proc. Royal Soc. B., 280, 20122659 (2013).

Jayasinghe, L., H.K. Abbas, M.R. Jacob, W.H. Herath and N.D. Nanayakkara: N-methyl-4-hydroxy-2-pyridinone analogues from Fusarium oxysporum. J. Nat. Prod.,3, 439-442 (2006).
Kalyani, P. and K.P. Hemalatha: In-vitro antimicrobial potential of Aspergillus niger. Int. J. ChemTech Res., 10, 430-435 (2017).

Kim, I.H., D.G. Lee, S.H. Lee, J.M. Ha, B.J. Ha, S.K. Kim and J.H. Lee: Antibacterial activity of Ulva lactuca against methicillin-resistant Staphylococcus aureus (MRSA). Biotechnol. Bioproc. Eng., 12, 579-582(2007).

Kyekyeku, J.O., S. Kusari, R.K. Adosraku, A. Bullach, C. Golz, C. Strohmann and M. Spiteller: Antibacterial secondary metabolites from an endophytic fungus, Fusarium solani JK10. Fitoterapia, 119, 108-114(2017).

Leelavathi, M., L. Vani and P. Reena: Antimicrobial activity of Trichoderma harzianum against bacteria and fungi. Int. J. Curr. Microbiol. Appl. Sci., 3, 96-103 (2014).

Leitão, A.L. and F.J. Enguita: Gibberellins in Penicillium strains: Challenges for endophyte-plant host interactions under salinity stress. Microbiol. Res., 183, 8-18(2016)

Leslie, J.F. and B.A. Summerell: The Fusarium Laboratory Manual. Blackwell Publishing, Oxford, United Kingdom (2006).

Liu, X.L., K.H. Huang, J.Z. Zhou, L. Meng, Y. Wang and L.X. Zhang: Identification and antibacterial characteristics of an endophytic fungus Fusarium oxysporum from Lilium lancifolium. Lett. Appl. Microbiol., 55, 399-406(2012).

Maadon, S.N., S.A. Wakid, I.I. Zainudin, L.S. Rusli, M.S. Mohd Zan, N.A. Hasan, N.A. Abu Shah, E.R. Rohani: Isolation and identification of endophytic fungi from UITM Reserve forest, Negeri Sembilan. Sains Malays., 47, 3025-3030 (2018).

Marcellano, J.P., A.S. Collanto and R.G. Fuentes: Antibacterial activity of endophytic fungi isolated from the bark of Cinnamomum mercadoi. Pharmacogn. J.,9, 405-409 (2017).

Mueller, G.M., G.F. Bills and M.S. Foster: Biodiversity of Fungi: Inventory and Monitoring Methods. Elsevier Academic Press, Burlington, MA (2004).

Nalini, M.S., N. Sunayana and H.S. Prakash: Endophytic Fungal diversity in medicinal plants of Western Ghats, India. Int. J. Biodiversity, 2014, 1-9(2014).

O'Neill, J.: Tackling Drug-Resistant Infections Globally: Final Report and Recommendations. Review on Antimicrobial Resistance, United Kingdom, 80 pages (2016).

Radić, N. and B. Štrukelj: Endophytic fungi - The treasure chest of antibacterial substances. Phytomedicine, 19, 1270-1284 (2012).

Rahaweman, A.C., J. Pamungkas, H. Madduppa, C. Thoms and K. Tarman: Screening of endophytic fungi from chlorophyta and Phaeophyta for antibacterial activity.IOP Conf. Ser.: Earth Environ. Sci., 31, 012026(2016)

Sadykova, V.S., A.V. Kurakov, A.E. Kuvarina and E.A. Rogozhin: Antimicrobial activity of fungi strains of Trichoderma from Middle Siberia. Appl. Biochem. Microbiol., 51, 355-361 (2015).

Saleh, R.M., S.A. Kabli, S.M. Al-Gharni and S. Mohamed: Screening and production of antibacterial compound from Trichoderma spp. against human-pathogenic bacteria. Afr.J. Microbiol. Res., 5, 1619-1628 (2011).

Schneider, P., M. Misiek and D. Hoffmeister: In-vivo and in-vitro production options for fungal secondary metabolites. Mol. Pharm., 5, 234-242 (2008).

Sondergaard, T.E., M. Fredborg, A.M. Oppenhagen Christensen, S.K. Damsgaard, N.F. Kramer, H. Giese and J.L. Sørensen: Fast screening of antibacterial compounds from fusaria. Toxins, 8, 355 (2016).

Strobel, G.A.: Rainforest endophytes and bioactive products. Crit. Rev. Biotechnol., 22, 315-333 (2002). 
Supaphon, P., S. Phongpaichit, V. Rukachaisirikul and J. Sakayaroj: Antimicrobial potential of endophytic fungi derived from three seagrass species: Cymodocea serrulata, Halophila ovalis and Thalassia hemprichii. PLoS ONE, 8, e72520 (2013).

Suryanarayanan, T.S.: Fungal endosymbionts of seaweeds. In: Biology of Marine Fungi (Ed.: C. Raghukuman). Progress in Molecular and Subcellular biology, Springer, Germany, pp. 53-69 (2012).

Tan, A.F., L.Y. Long, K. Nagahawatte and M. Müller: Shades of fungi - A review of pigments from endophytic fungi. Malays. J. Microbiol., 14, 70-79 (2018).

Tayung, K., B. Barik, D. Jha andD. Deka: Identification and characterization of antimicrobial metabolite from an endophytic fungus, Fusarium solani isolated from bark of Himalayan yew. Mycosphere, 2, 203-213 (2011)

Vandepitte, J., J. Verhaegen, K. Engbaek, P. Rohner, P. Piot, C.C. Heuck and C.C. Heuck: Basic Laboratory Procedures in Clinical Bacteriology. $2^{\text {nd }}$ Edn., WHO, Geneva (2003). doi:10.3390/nu 10091213

Waqas, M., A.L. Khana, M. Hamayuna, R. Shahzad, S.M. Kang, J.G. Kim andl.J. Lee: Endophytic fungi promote plant growth and mitigate the adverse effects of stem rot: An example of Penicillium citrinum and Aspergillus terreus. J. Plant Interact., 10, 280-287 (2015).

Wicklow, D.T., S. Roth, S.T. Deyrup and J.B. Gloer: A protective endophyte of maize: Acremonium zeae antibiotics inhibitory to Aspergillus flavus and Fusarium verticillioides. Mycol. Res., 109,
610-618 (2005).

Wohlleben, W., Y. Mast, E. Stegmann and N. Ziemert: Antibiotic drug discovery. Microb. Biotechnol., 9, 541-548 (2016).

World Health Organization: World Health Statistics Overview 2019: Monitoring Health for the SDGs Sustainable Development Goals (No. WHO/DAD/2019.1). WHO, Geneva (2019).

Zainee, N.F.A., N. Ibrahim and A. Ismail: Diversity of Seaweed Endophytic Fungal Isolations. UKM Press, Bandar Baru Bangi, Selangor, Malaysia (2019a).

Zainee, N.F.A., N. Ibrahim, A. Ismail, M.E. Taip and A. Ismail: Diversity of endophytic fungi isolated from the leaves, stipes and receptacles of the Malaysian marine brown algae, Sargassum (Phaeophyta, Sargassaceae). Malayan Nat. J., 71, 139-148 (2019b).

Zainee, N.F.A., N. Ibrahim, A. Ismail, M.E. Taip andA. Ismail: Kepelbagaian kulat endofit daripada Ulva lactuca: Alga hijau dominan di Malaysia. Malays. Appl. Biol. J., 47, 41-45 (2018).

Zainuddin, N., S.A. Alias, C.W. Lee, R. Ebel, N.A. Othman, M.R. Mukhtar andK. Awang: Antimicrobial activities of marine fungi from Malaysia. Botanica Marina, 53, 507-513 (2010).

Zhang, H., X. Sun and C. Xu: Antimicrobial activity of endophytic fungus Fusarium sp. isolated from medicinal honeysuckle plant. Arch. Biol. Sci., 68, 25-30 (2016).

Zhang, X.Y., Y. Zhang, X.Y. Xu and S.H. Qi: Diverse deep-sea fungi from the South China Sea and their antimicrobial activity. Curr. Microbiol., 67, 525-530 (2013). 